\title{
TOTAL DISSOLVED SOLIDS IN AN OHIO MINED AREA ${ }^{1}$
}

\author{
Jonathan Peterson ${ }^{2}$
}

\begin{abstract}
At a mined area in northeastern Ohio, Total Dissolved Solids (TDS) concentrations within a large creek and its tributary sometimes exceeded the local regulatory limit. The TDS stemmed from active and inactive coal mines and their settling ponds, from which dissolved loads were carried to the creek and tributary via outfalls. The existing compliance strategy was to control the timing of problematic outfalls, reducing flows when exceedance was imminent; however, because of the variability of weather and mining activities, identifying the problematic outfalls would require more frequent measurements than could be performed manually.

Data logging stations were deployed on the creek and the tributary between each mining outfall, and specific conductivity (for TDS) and pressure (for flow) were recorded at 10-minute intervals. Field testing resulted in an innovative design for the data logger housing. A telemetry station was installed to provide real-time warnings should TDS-thresholds be exceeded downstream of the coal mine. Data analysis included calculations of mass loading and the annual TDS delivered by each outfall. Results indicated four outfalls whose mass loads were particularly problematic, and that TDS was occasionally resultant from an unknown source located upstream of the coal mines. Recommendations are included regarding the designs of systems.
\end{abstract}

\section{Additional Key Words:}

${ }^{1}$ Oral paper presented at the 2016 National Meeting of the American Society of Mining and Reclamation, Spokane, WA, Reclaiming the West, June 4-9, 2016. R.I. Barnhisel (Ed) Published by ASMR; 1305 Weathervane Dr., Champaign, IL 61821.

2 Jonathan Peterson, Geologist, Sovereign Consulting Inc., Seattle, WA, 98121. Journal American Society of Mining and Reclamation, 2016 Volume 5, Issue 1 pp 86 - 110 DOI: http://doi.org/10.21000/JASMR16010086 


\section{Introduction}

Setting

This project is part of a permit review (NPDES), and names and locations are kept confidential per the client's request. The Site is located in temperate, northeastern Ohio on the Pittsburgh Coal Seam (Rupert et al., 1999) and consists of two coal mines with surface and underground workings that are adjacent to waterways designated herein as the Creek and the Tributary (Figs. 1 and 2). Flows within the 30-mile-long Creek ranged from about 2 to 5,000 cubic feet per second (cfs) in 2015. There is some correlation of local rain events with the timing of flows in Site-proximal waters, but the quantity of rainfall per event correlates poorly with the magnitudes of those flows.

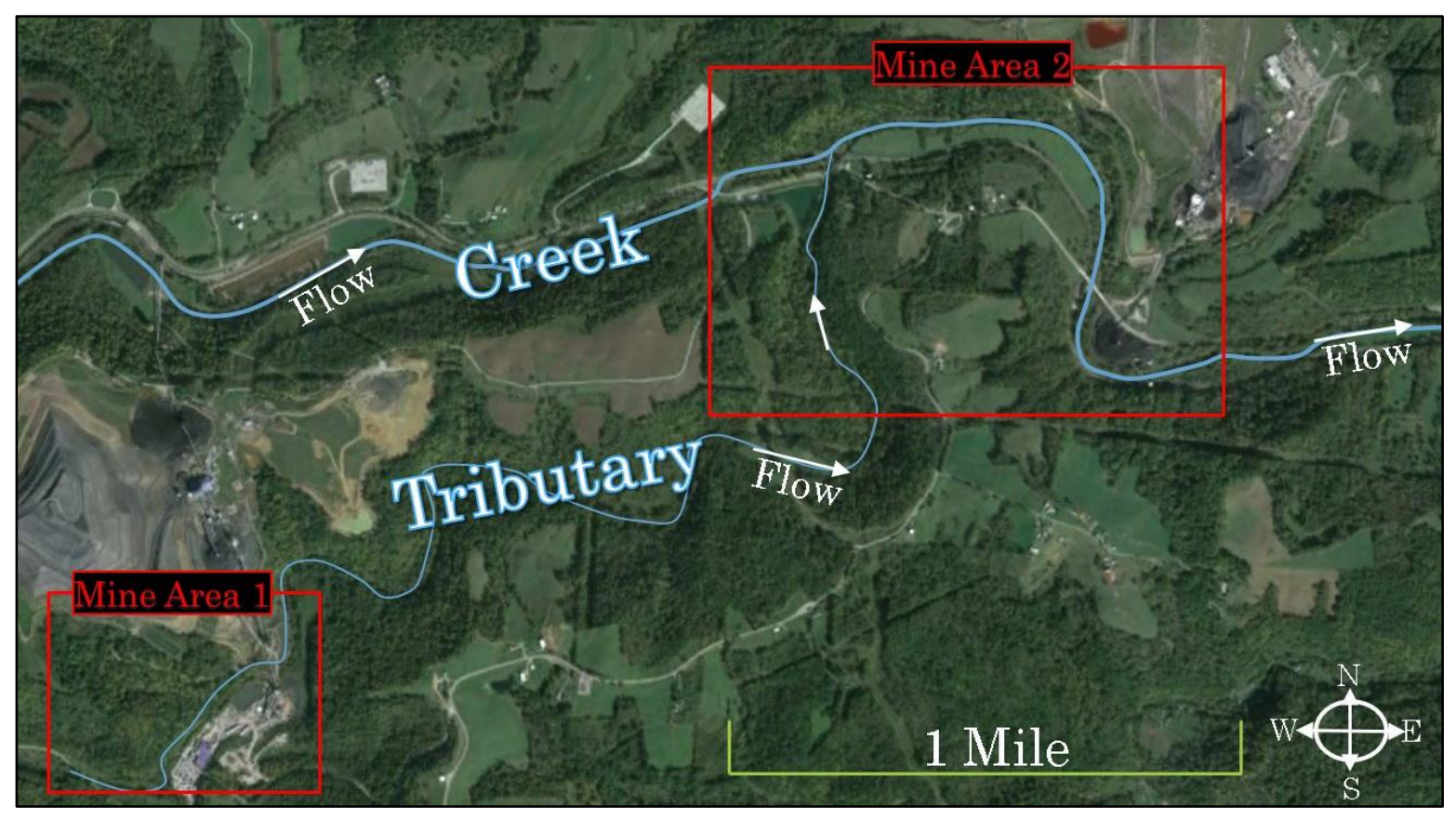

Figure 1. The mines and waterways; investigation areas are boxed in red.

Near the Site, large piles of waste rock with refuse coal store rainwater and release products of mineral dissolution as part of year-round effluent seepage (Smith et al., 1995; Ritchie, 1994; Lefebvre et al., 2001). Active mining processes also generate wastewater containing dissolved ions. The discharges resulting from these inactive and active sources, joined by runoff, enter settling ponds and then travel into Site-proximal waterways via "outfalls" (Fig. 3). Site operations draw water from the Creek and Tributary at "intake" points. The cumulative effect is that TDS in the Creek and Tributary occasionally exceeds the local regulatory limit of 1,500 milligrams per 
liter $(\mathrm{mg} / \mathrm{L})$, usually in the relatively dry conditions of late summer. Main components of the TDS are sulfate, sodium, and chloride.

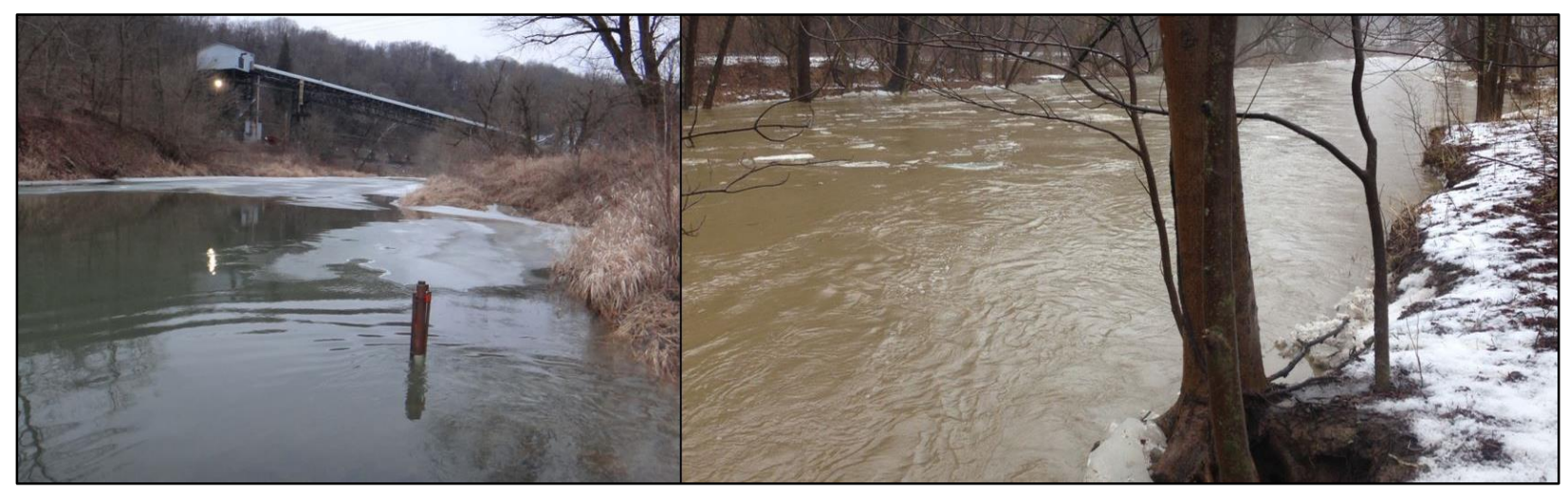

Figure 2. Coal conveyor and original monument (left); Creek approaching bankfull level (right).

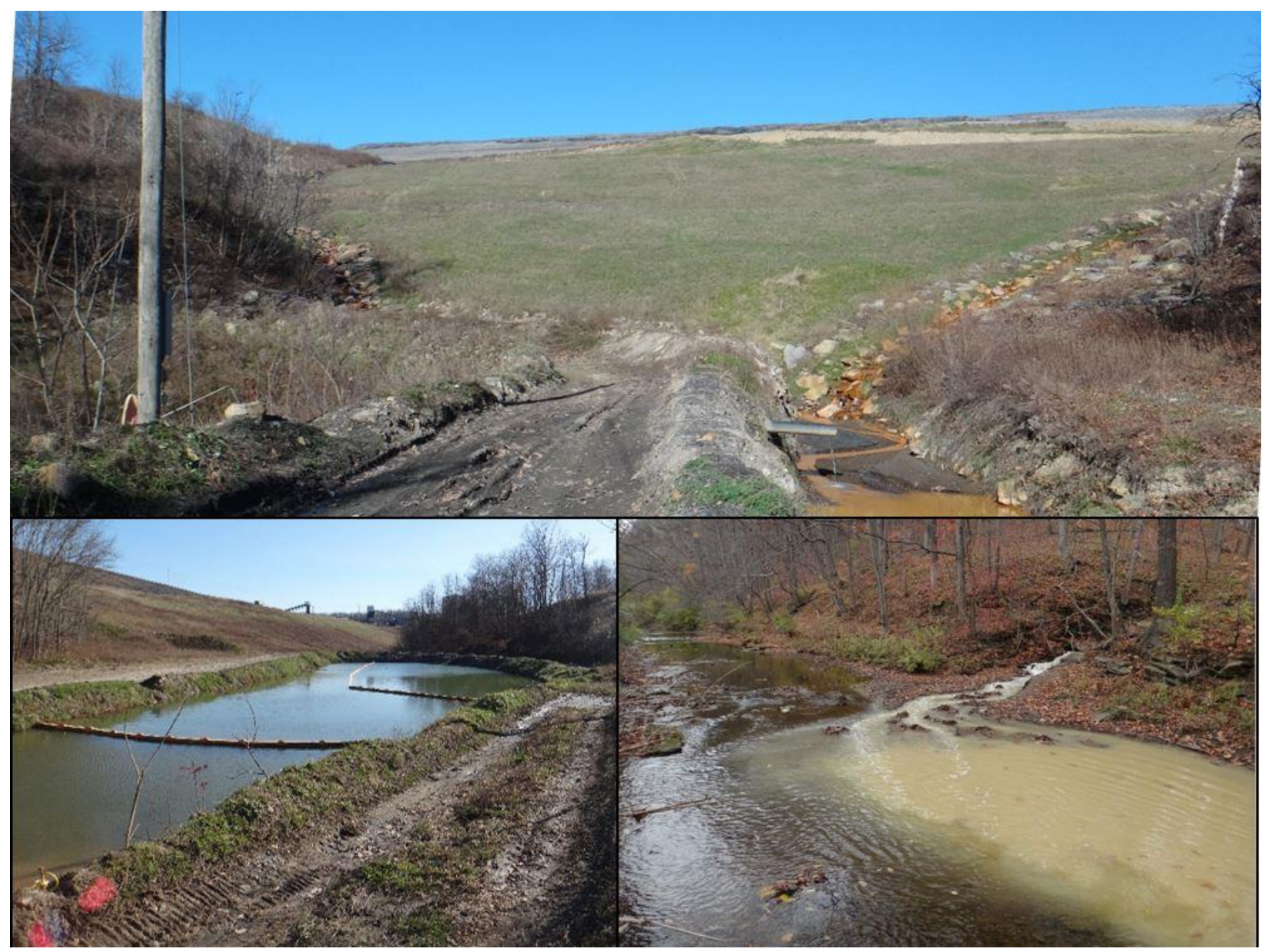

Figure 3. Waste rock refuge (top); Settling pond (lower left); Outfall from Pond 1 (lower right). 
JASMR, 2016 Volume 5 Issue 1

\section{Objectives}

The initial plan was to alter the timing of discharges, provided that flows could be restricted at key outfalls during relatively dry conditions. However, the problematic outfalls were not consistently identified in the results of sporadic, manual sampling in 2014. Hundreds, or even thousands, of measurements would be needed to accurately prioritize the sources of TDS for the varied weather and Site-operating conditions. The modified plan includes:

- Establishing a telemetry station on the Creek to begin testing corrective measures; and

- Installing a data-logging system to measure TDS and flow at 10-minute intervals. The logged data are the basis for an outfall management strategy under varying conditions and are needed to ascertain whether offsite problems are impeding onsite remediation efforts.

\section{Methods}

\section{January 2015 Fieldwork}

Eleven data logging stations were installed on the Creek and Tributary between mining outfalls and intakes in order to isolate the influences upon the receiving waterway (Figs. 4 and 5). In selecting a specific site for a data logging station, the location had to be safely accessible, located on a moderately straight stretch of water, protected from the impact of floating debris, of sufficient depth to have water year round, and supplied with a slight stream current for the specific conductivity sensor.

Each station consisted of a conductivity logger (for TDS) and a pressure logger (for flows). To keep costs low in the context of an unsecured site, data loggers with optical uploading interfaces were selected instead of comparably more-expensive wireless loggers. The loggers were originally housed in three-inch, vertical, schedule 40 PVC monuments that were pinned into bedrock with rebar rods. The loggers were suspended within the monuments by $1 / 16$ " stainless steel cables with carabiner-style clips at each end. PVC caps were padlocked to the tops of the monuments. 
JASMR, 2016 Volume 5 Issue 1

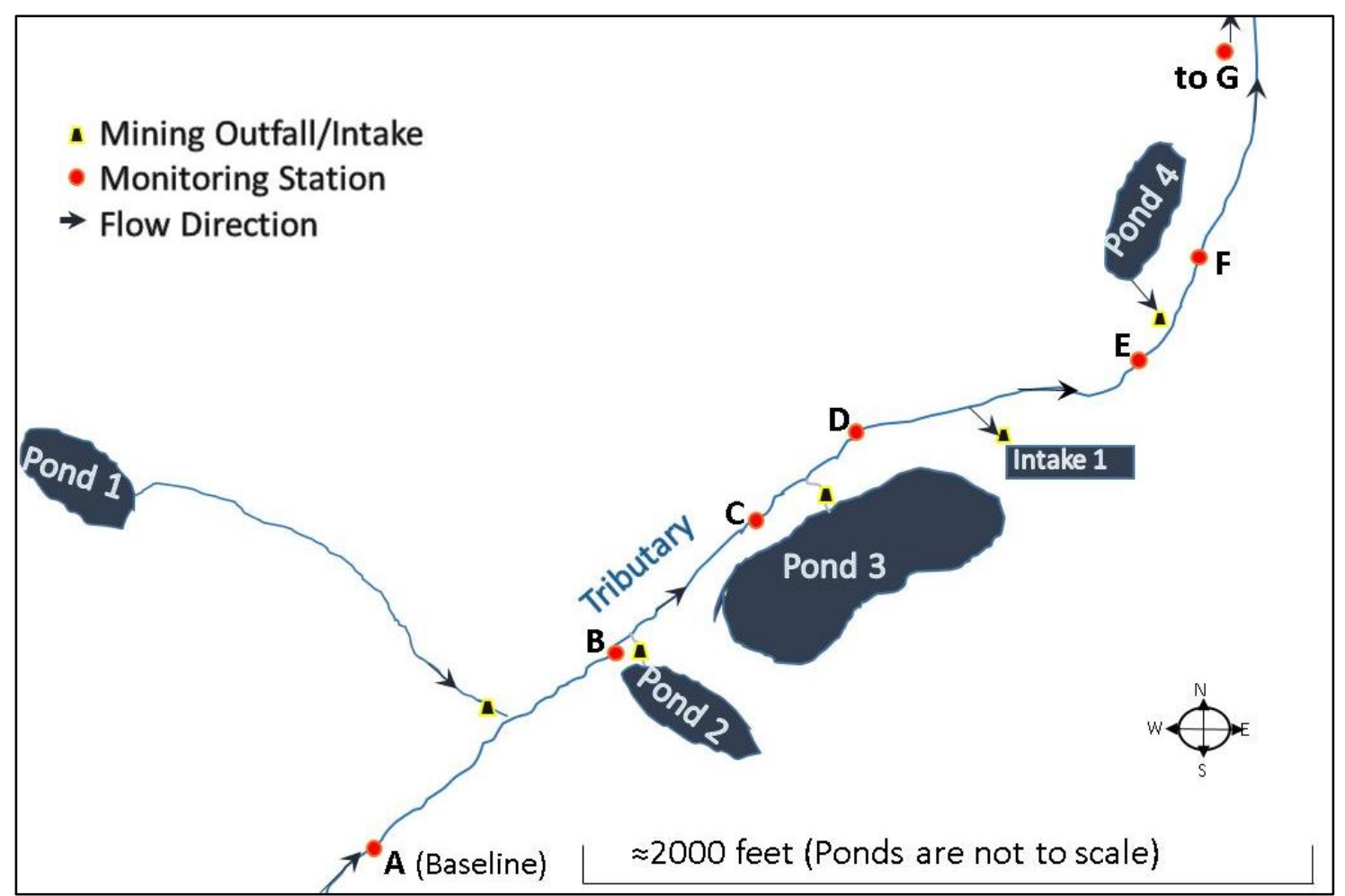

Figure 4. Map of mining structures and monitoring stations proximal to the Tributary.

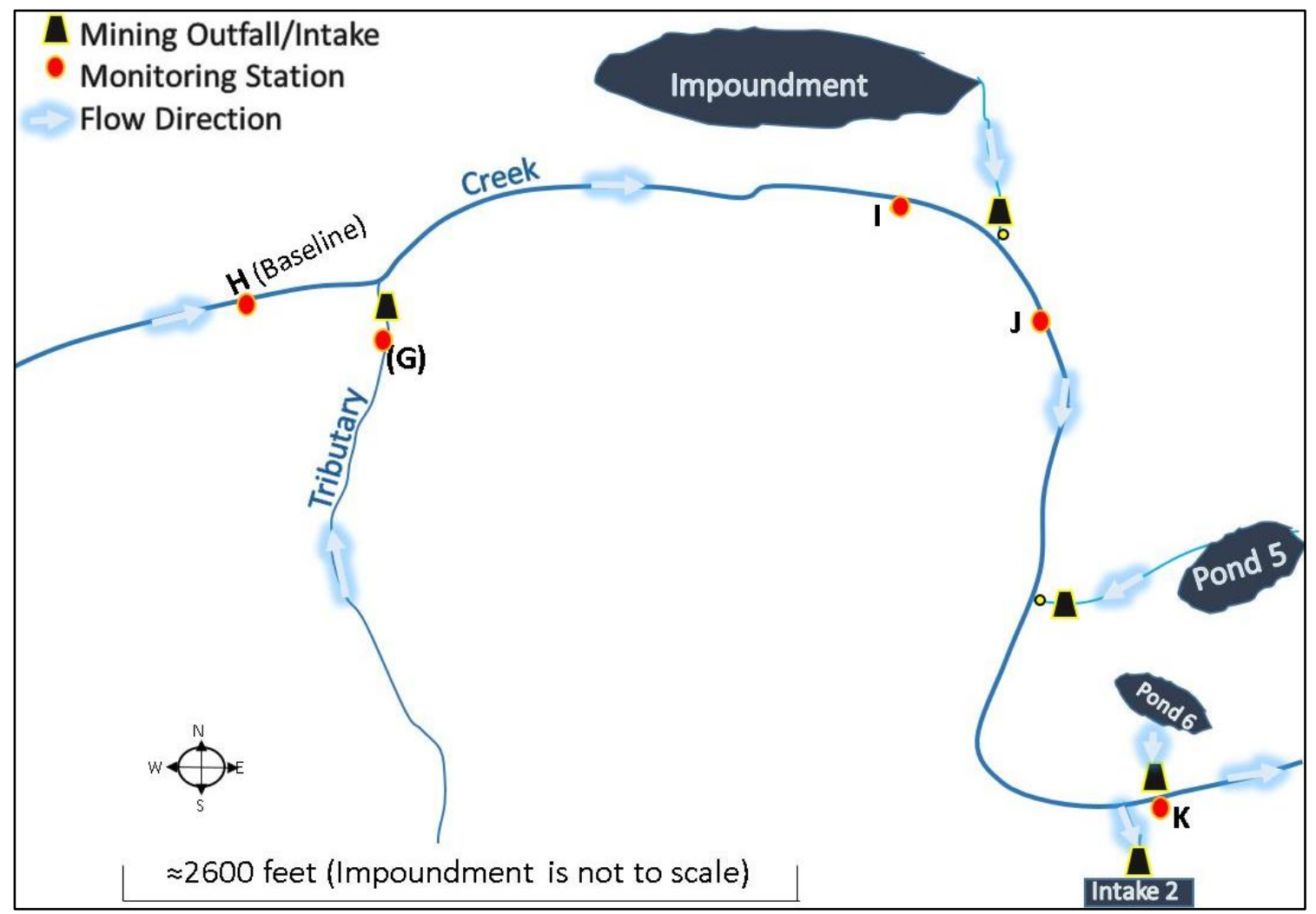

Figure 5. Map of mining structures and monitoring stations proximal to the Creek. 


\section{March 2015 Fieldwork}

Although Site compliance had not been a problem during the higher-flow conditions of winter, data loggers had been launched in late January so that the testing of data logging monument designs and the suitability of chosen monitoring locations could be resolved prior to the onset of lowerflow conditions. By late February, occasional flat-lining was observed in the data retrieved from four data logging stations, caused when loggers became surrounded by ice. By late March, the vertical monuments had sustained damage from multiple floods (Fig. 6), which were occurring more frequently than had been anticipated, and the monuments were subsequently redesigned and replaced. These events produced sporadic gaps in the data sequences between January and March.

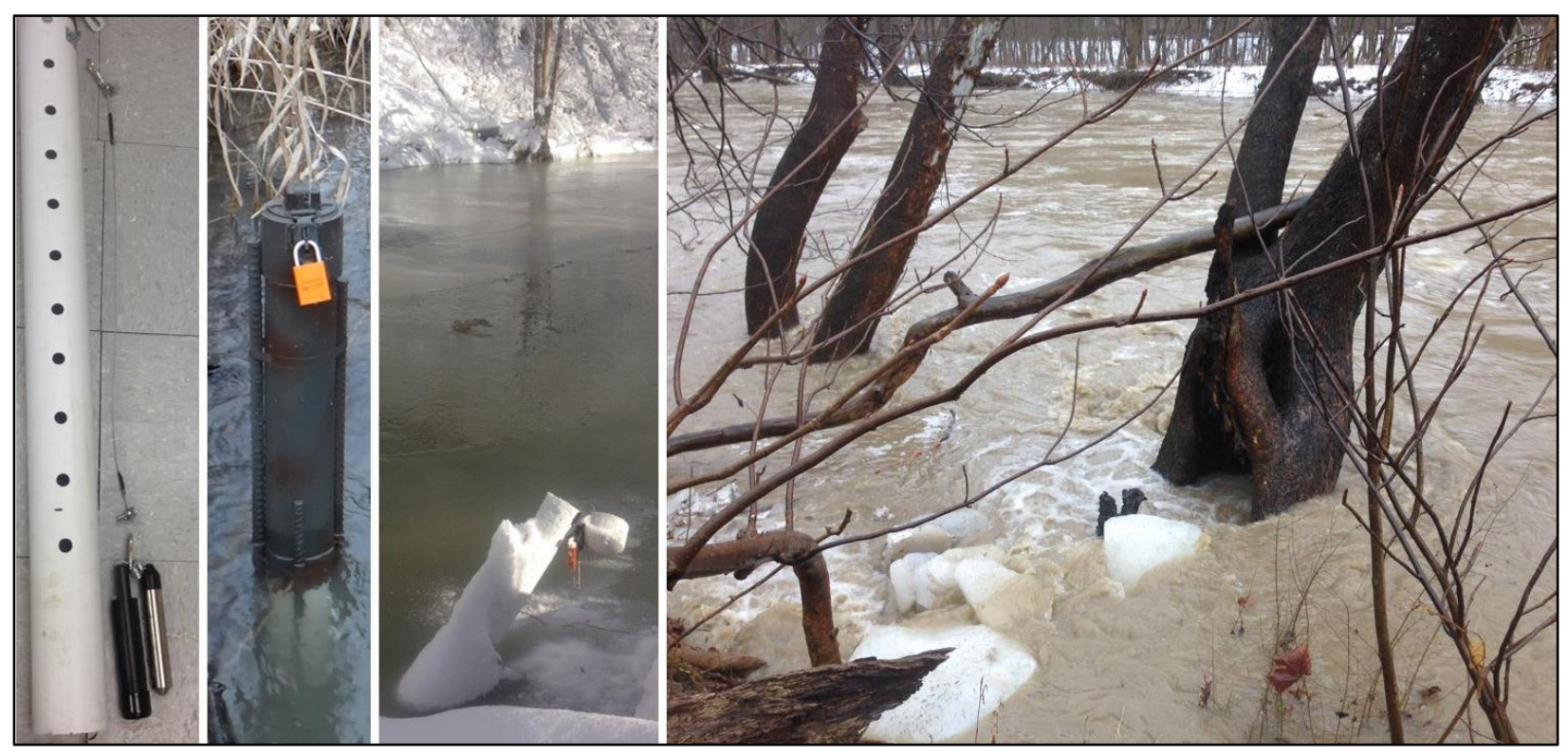

Figure 6. Design and damage to original monuments (left); flooding (right).

Vertical monuments proved susceptible to collisions by logs and ice, and ice often built up around and inside of them. It was also inevitable that the cables suspending the data loggers within the vertical monuments became stretched in length (Miles, 2009), which would affect the consistency of logged pressures. Newly designed monuments were relatively lower in profile and of a stronger build quality than their vertical predecessors; the new monuments were installed horizontal to the stream bed and made of two-inch schedule 80 PVC. This design allowed the logging stations to be placed well away from shore, which helped to supply conductivity loggers with water current and reduce the buildup of silt within the monument. The new monuments had 
the added benefit of a removable sleeve, providing quick access for data transfer and ensuring that the pressure logger was returned to its original height (Fig. 7).

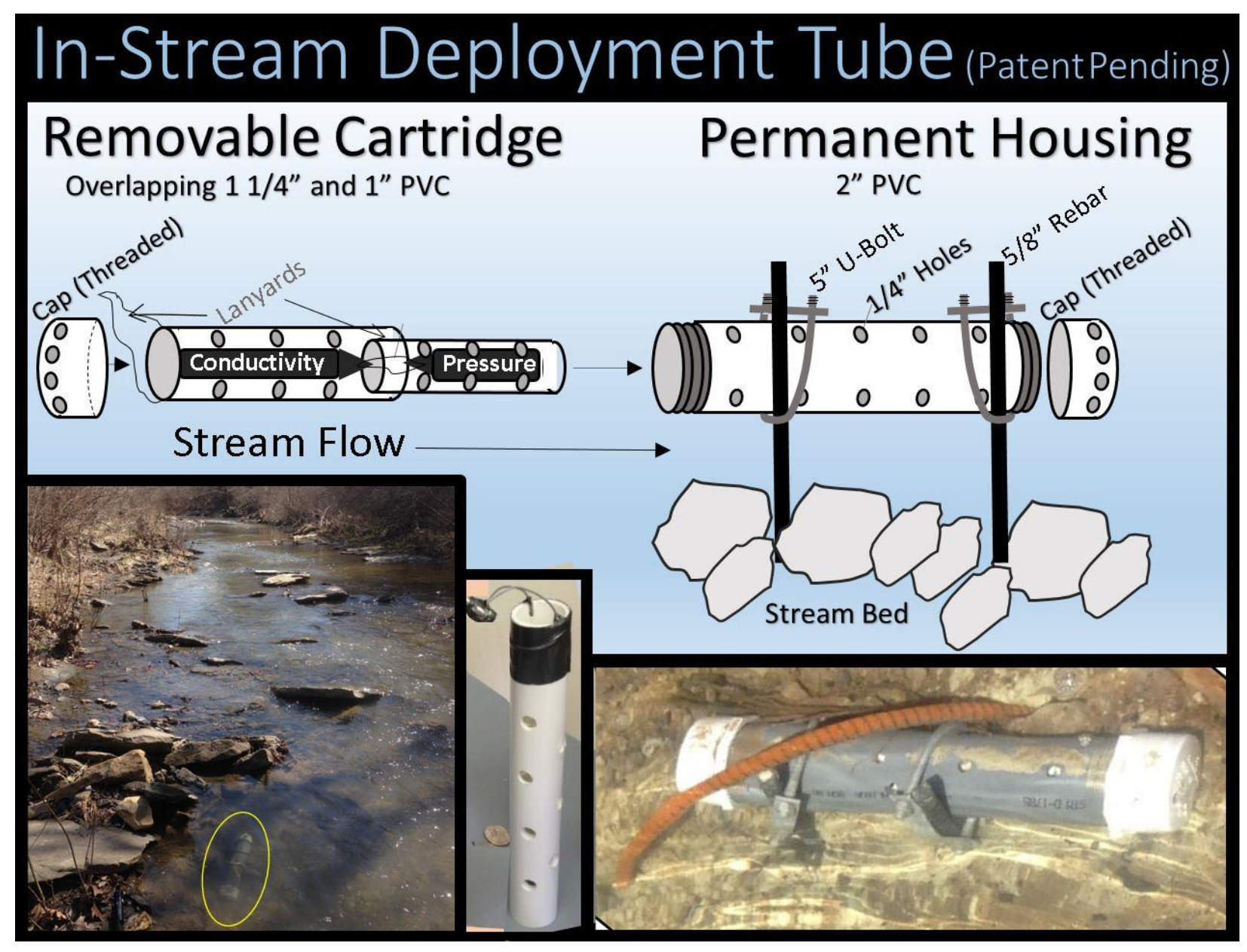

Figure 7. Revised monument design (product information available on request).

April - November 2015 Fieldwork

The logging system ran continuously between April and late November with few exceptions. Landslide damage caused several weeks of missed data for one logging station. Three conductivity loggers read erratically during different three-week spans in the summer but then recovered; the sensors were either blocked or had gone dry. The resultant data gaps were filled using data that were simultaneously logged from the next downstream station, and these substitutions are discussed in the "results section." The routine fieldwork included maintenance visits that were conducted about once per month to de-silt monuments and upload data. Uploaded data were then added to a running timeline and graphically plotted to expose anomalies. 
A battery-powered telemetry station went online in May, and began real-time monitoring of TDS in the Creek and sending daily data (10-minute readings). The telemetry system was a monitoring tool for potentially managing mining outfalls, and not used for any official compliance reporting. A telemetry system was selected that could be concealed inside a vertical monument and whose modem and data logger had been tested together. Notifications indicated when a programmed TDS threshold had been crossed (Fig. 8).

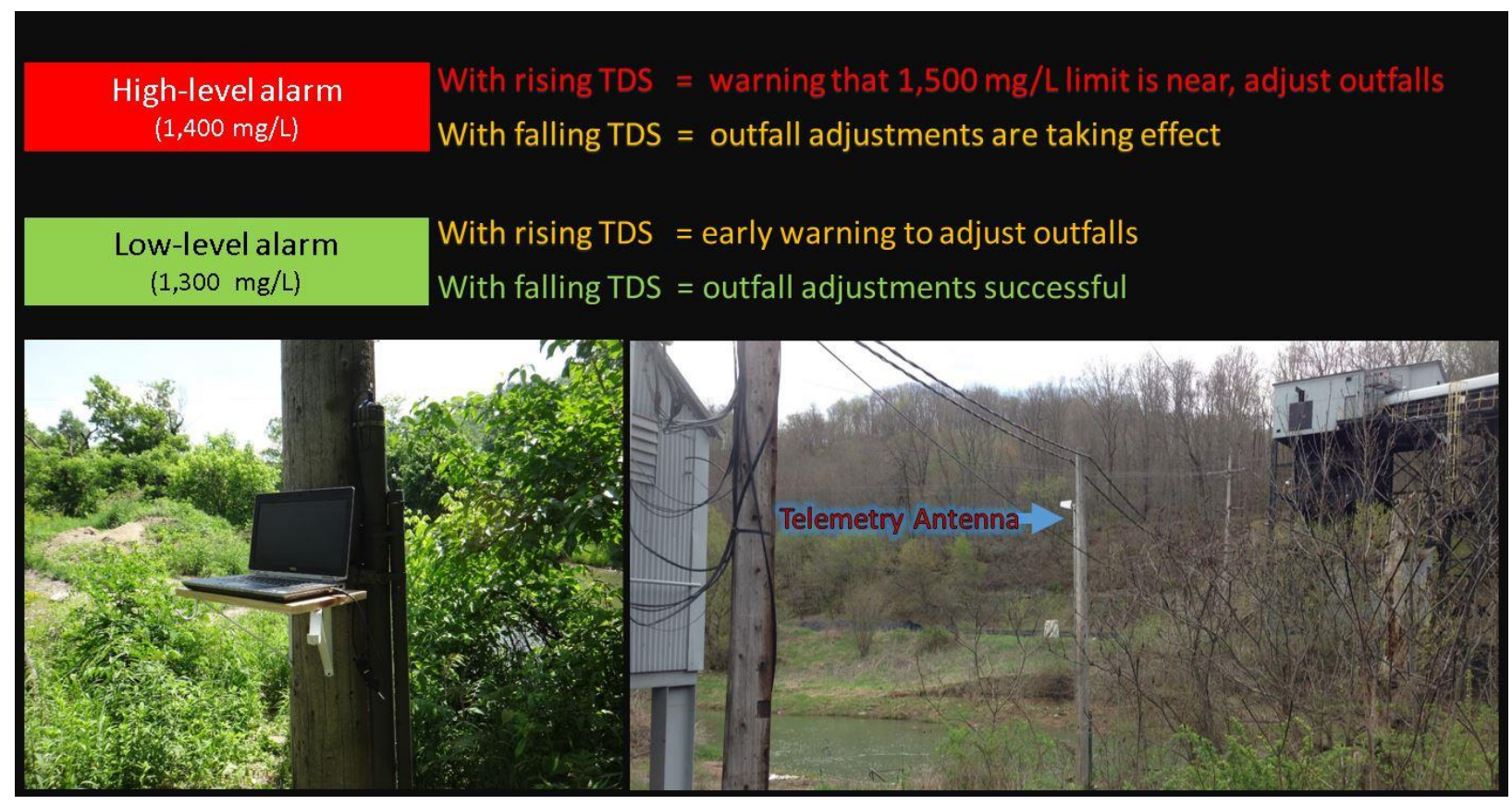

Figure 8. Telemetry settings and system photos.

During the installation of the telemetry system, a test monument had been destroyed in a flood, and the installation location had been moved upstream and adjacent to permanent structures (Fig. 9). Software settings had been temperamental, and the wireless coverage had been less than $5 \%$ strength until a specialized antenna was installed. One other adjustment included simplifying the warning notifications to report only the TDS values to the client. Since May of 2015, the client was notified whenever the TDS in the Creek approached or exceeded the regulatory limit of 1,500 mg/L; exceedances occurred in early June, early August, throughout September, mid-October, and mid-November. Upon notification, the client reduced certain activities, but the most effective response was not yet determined. 


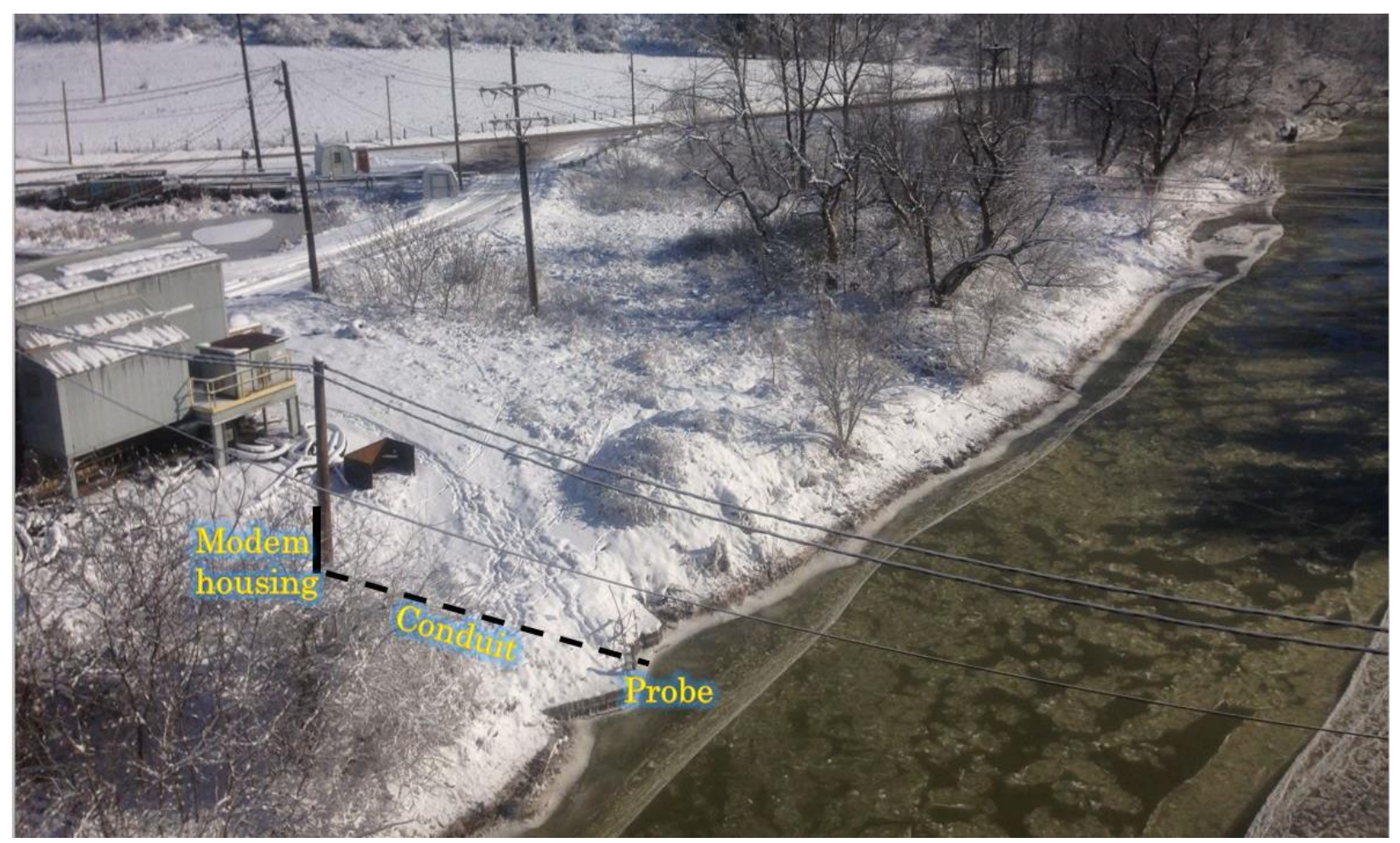

Figure 9. Final location of telemetry station (station K).

\section{$\underline{\text { Methodology for Flows }}$}

Measurements of flows and sensor depths were obtained by manual, wading methods as part of monthly maintenance events. This involved measuring across a straight stretch of waterway, and measuring depths and velocities. Waterway flows were calculated using the midsection approach to the standard velocity-area method as described by Turnipseed and Sauer (2010). These became reference points used to convert logged sequences of pressures to flows. Each station had a unique conversion (polynomial line slope) between pressure and flow, owing to the different range of stream depths at each data logging station. Flows were barometrically compensated using Hoboware data logging software, and the results compared well with flows of the USGS for a gage located on the Creek downstream of the Site.

The accuracy of flows was limited by the method and the logistics, which included placing the data loggers in active stream locations (not behind weirs), performing judgment-based field measurements, and installing data loggers in comparatively dissimilar types of creek channels due to the locations of existing outfalls. The margin of error is estimated at $10 \%$, which is sufficiently accurate for the project goal of finding significant differences in flow between successive stations. 
JASMR, 2016 Volume 5 Issue 1

\section{Methodology for TDS}

The accuracy of reported TDS values was limited by the use of linear conversions (Radtke et al., 2005). However, some inaccuracy was acceptable given that the data logging and telemetry components of this project were intended as screening tools to detect significant increases in TDS, and not for official compliance. The selected equipment could only obtain TDS as converted from specific conductivity; hence, the accuracy of TDS values depended on:

- Consistent calibration of the conductivity loggers; and

- Selecting a conversion factor appropriate for the site-specific chemistry.

The calibration of conductivity loggers was checked monthly at each data logging station by comparing the in-stream data logger reading with that of a handheld multimeter, and by comparing the readings logged before and after cleaning. If the readings were inconsistent, the data logger was bench-tested with calibration standards. For this investigation, all data anomalies were related to external factors such as freezing or waterways going dry. Stratification of conductivity in waterways was not detected.

The conversion from conductivity to TDS is imperfect, as it constitutes a linear approximation of a nonlinear function (e.g., Walton, 1989). For freshwater sites it should be between 0.55 to 0.70, depending on site-specific chemistry (Hem, 1970; Thirumalini, 2009). The analysis of four laboratory-analyzed samples suggests that the appropriate site-specific conversion is 0.60 (Fig. 10), although additional samples are needed to establish this. For processing the 2015 data, a conversion of 0.65 was selected to agree with built-in conversions in equipment, and because overestimating TDS was preferable to underestimating it. All conductivity data were converted to TDS using equation 1, consistent with Lieberman et al. (1987):

$$
\mathrm{TDS}=\mathrm{r} \mathrm{K}
$$

where TDS = Total Dissolved Solids (mg/L); r = site-specific conversion (dimensionless); $\mathrm{K}=$ specific conductivity (microsiemens per centimeter). 
JASMR, 2016 Volume 5 Issue 1

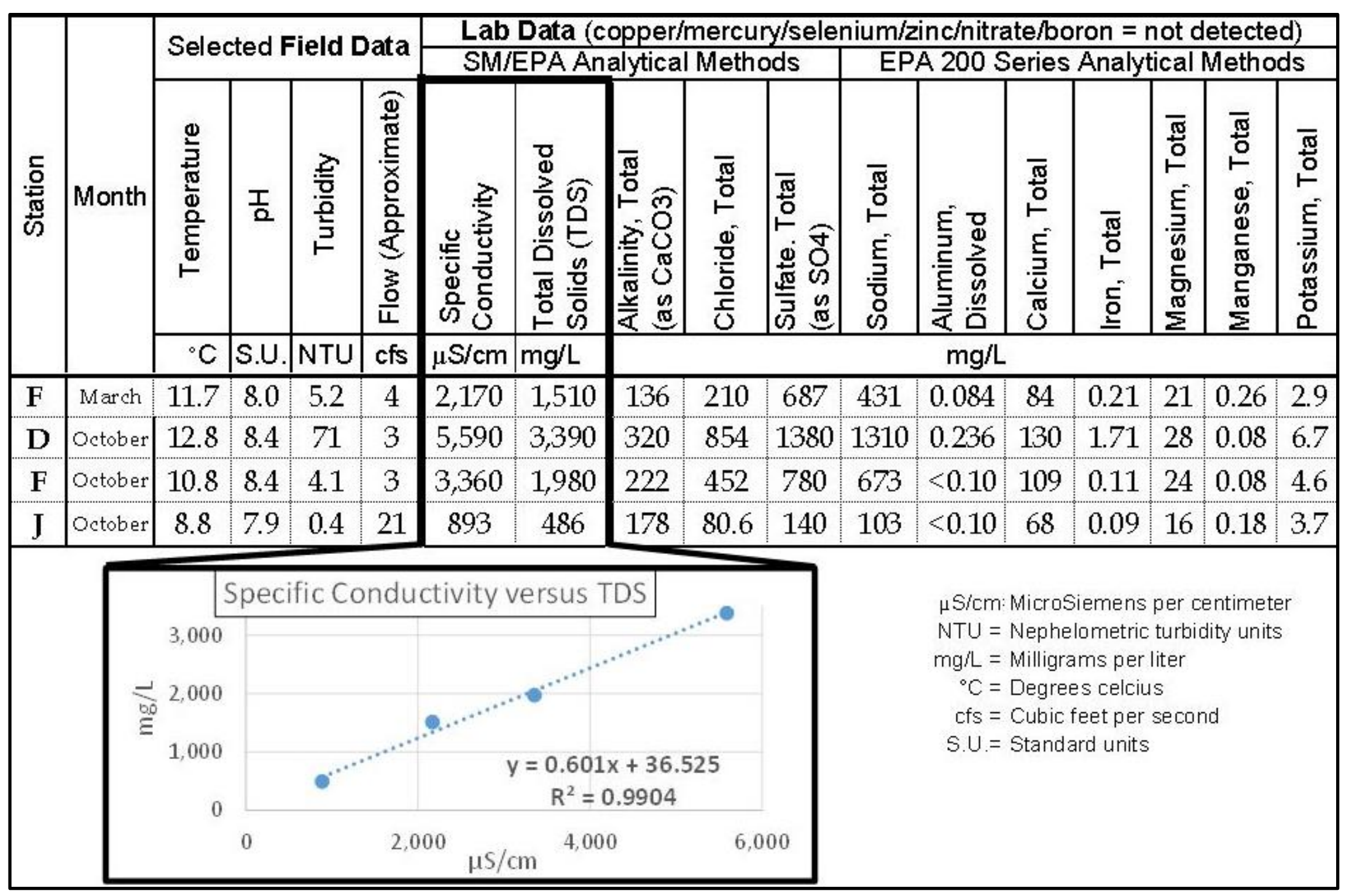

Figure 10. Laboratory results for TDS, conductivity, and other detected substances. 
An additional note, the results in Fig. 10 show that sulfate and sodium concentrations were relatively abundant, and that chloride concentrations were also significant. While the composition of the TDS will be investigated further, the focus of the investigation has been on methodological consistency and comparing relative abundances.

\section{$\underline{\text { Results }}$}

\section{Logged Data}

Figures 11 and 12 present the data sequences logged in 2015 for conductivity converted to TDS and pressure converted to flow. Plots for each station are positioned in consecutive order of flow, with the uppermost plot as a relative baseline and the lowermost plot as the cumulative composition for the respective waterway. The areas where larger gains in TDS occurred are noted. For Fig. 11:

- there are about 50 occasions when TDS doubled between baseline station A and station B, indicating influence on the Tributary from Pond 1;

- TDS was frequently increased by an order of magnitude between stations B and C, indicating significant influence on the Tributary from Pond 2;

- Pond 3 apparently had a low influence on the Tributary for most of the past year, as seen from stations $\mathrm{C}$ to $\mathrm{D}$;

- the influence of Pond 4 on the Tributary was apparently moderate and nearly constant, as seen from stations $\mathrm{E}$ to $\mathrm{F}$; and

- for nearly all of the data sequences with gaps and substitutions (*) there is a redundant data set; that is, the data of stations $\mathrm{D}$ and $\mathrm{F}$ are nearly identical to that of stations $\mathrm{E}$ and $\mathrm{G}$, respectively. The substitutions included interpolation and were made with respect to the trends and magnitudes in the rest of the original data set. 
JASMR, 2016 Volume 5 Issue 1

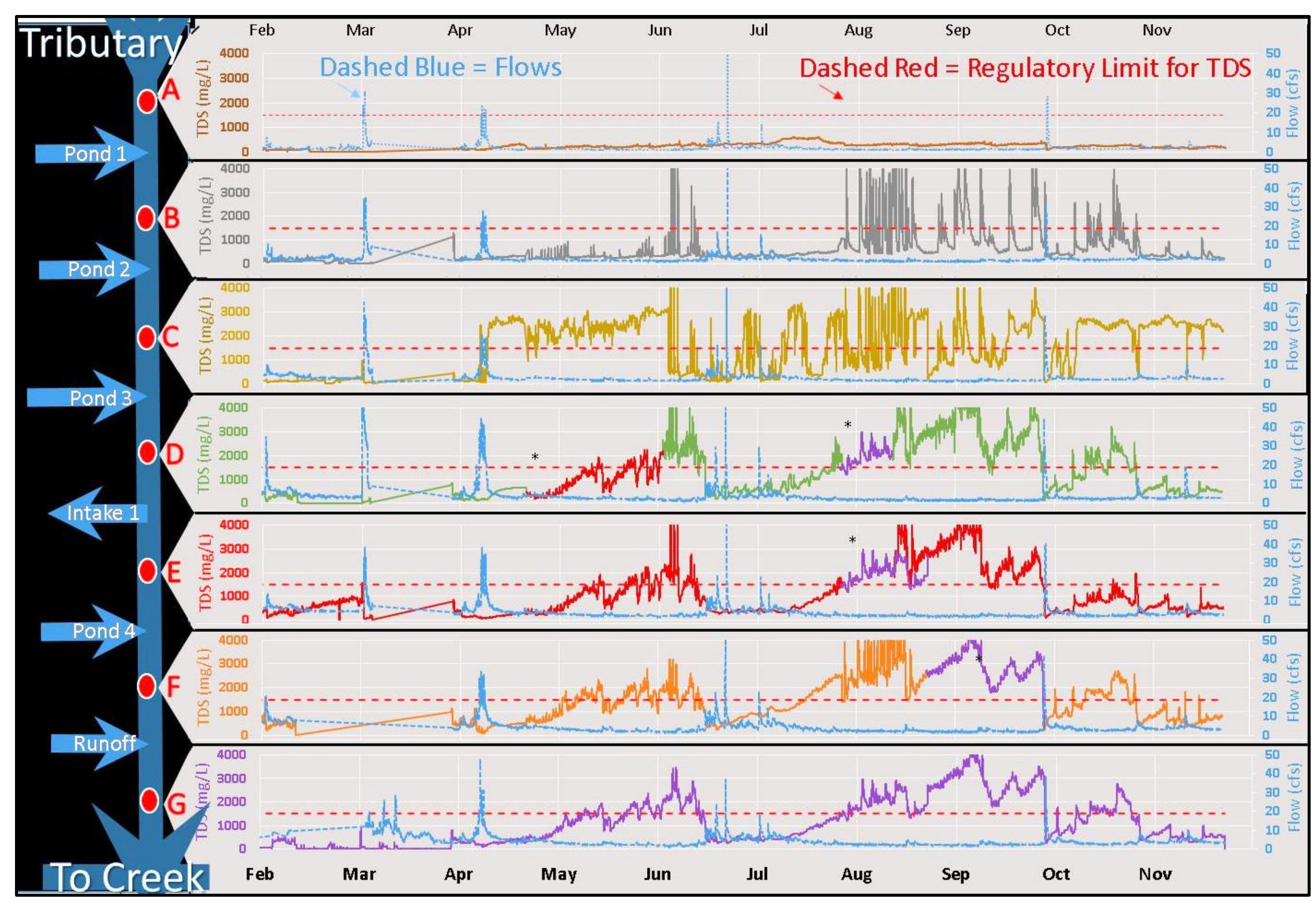

Figure 11. Logged data on the Tributary (baseline at top). (*Where data were missing, the color-coding indicates the donor dataset.) 
JASMR, 2016 Volume 5 Issue 1

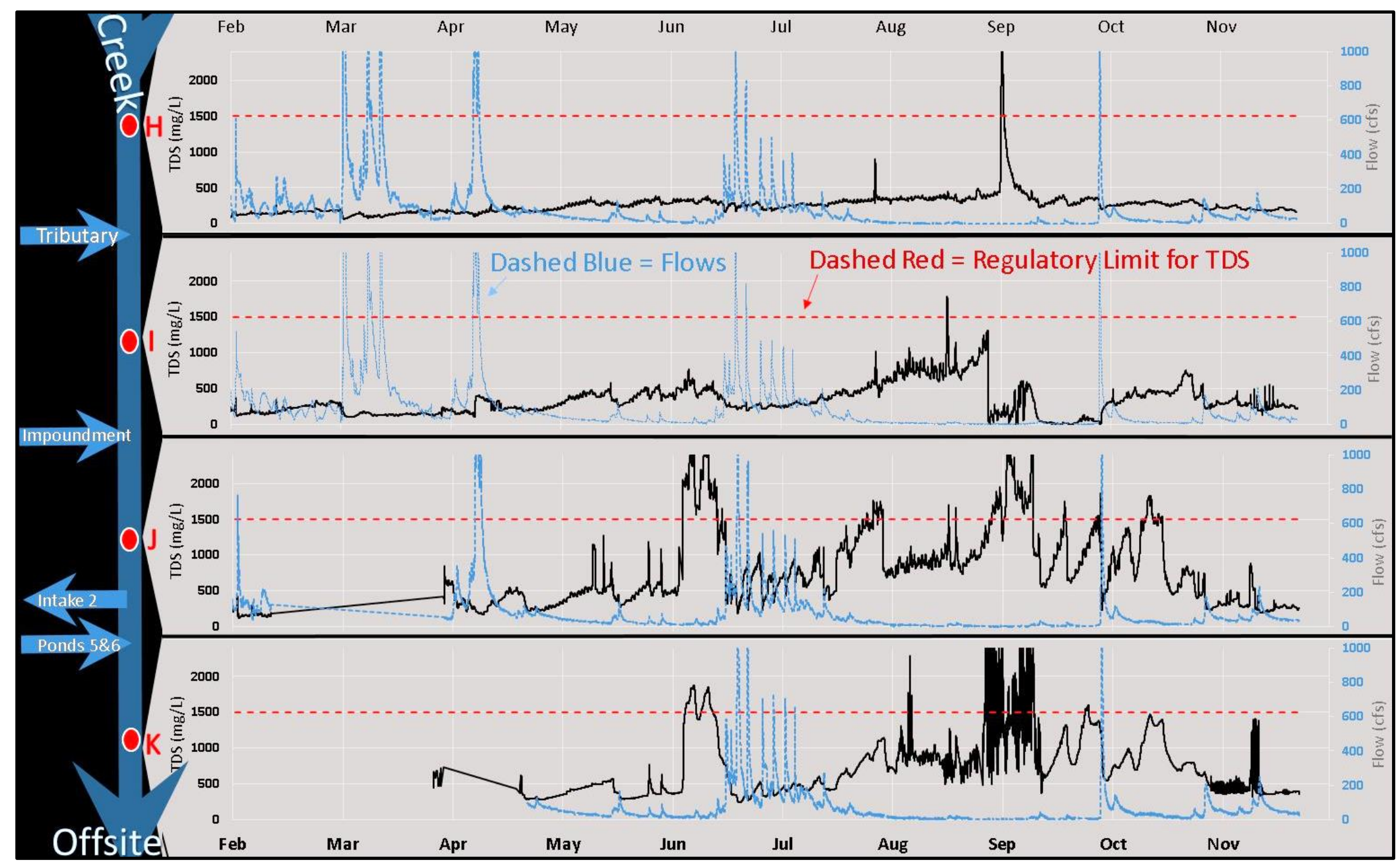

Figure 12. Logged data on the Creek (baseline at top). 
For Fig. 12:

- TDS typically increased by about $500 \mathrm{mg} / \mathrm{L}$ between baseline station $\mathrm{H}$ and station $\mathrm{I}$, indicating a comparatively moderate influence of the Tributary on the Creek;

- TDS sometimes increased by over $1,000 \mathrm{mg} / \mathrm{L}$ between stations I to $\mathrm{J}$, as on June $15^{\text {th }}$, indicating that the influence of the Impoundment to the Creek can be large;

- offsite-derived TDS was noted at baseline station H in late July and early September; and

- TDS readings were unstable at station K (telemetry site) during mid-September but then improved. This coincided with attempted pumping at Intake 2 while the Creek was going dry. A similar sequence of events occurred again in late October.

Though not included, a plot of all flows by date yielded very well-grouped results, and the differences between the flows of successive stations usually were less than the estimated $10 \%$ margin of error. By contrast, the TDS values varied significantly between many stations. The combined flows and TDS concentrations formed the basis for the mass loading calculations that follow, and these calculations enabled quantifiable conclusions.

Mass Loading Calculation and Flow Assignment

As per the following figures, the stretches of the Tributary and Creek that received the greatest mass loading were determined by comparing the relative gains or losses between each adjacent pair of data logging stations. Mass load is presented as equation 2, consistent with Lieberman et al. (1987), and modified to equation 3 to yield the difference $(\Delta)$ in mass load:

$$
\mathrm{ML}=\mathrm{Q} \text { r K, or } \mathrm{ML}=\mathrm{Q} \text { TDS }
$$

where, $\mathrm{ML}=$ mass loading in kilograms per day $(\mathrm{kg} /$ day $) ; \mathrm{Q}=$ flow in cfs; TDS in mg/L

$$
\mathrm{ML}_{\mathrm{d}}-\mathrm{ML}_{\mathrm{u}}=\Delta \mathrm{ML}
$$

where, $\mathrm{ML}_{\mathrm{d}}=$ mass load downstream in $\mathrm{kg} / \mathrm{day}, \mathrm{ML}_{\mathrm{u}}=$ mass load upstream in $\mathrm{kg} / \mathrm{day}$; and $\Delta \mathrm{ML}$ in $\mathrm{kg} /$ day

The results were also differentiated according to low, moderate, and high flows, based on corresponding flows at the USGS station of 0 to $25 \mathrm{cfs}, 25+$ to $200 \mathrm{cfs}$, or $200+\mathrm{cfs}$, respectively. Mass loads during the high flow are not problematic for compliance, and are omitted from this section for brevity. 


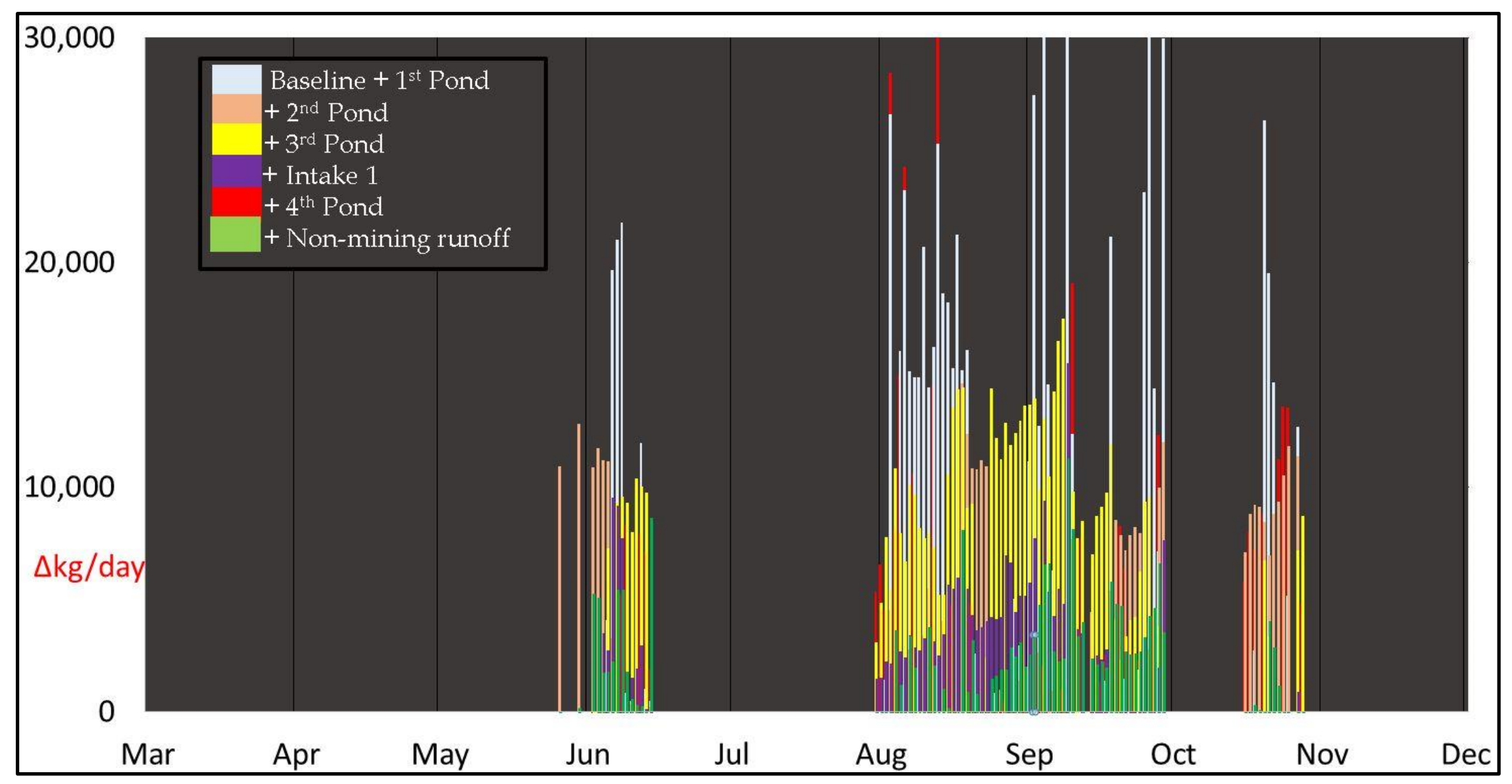

Figure 13. $\Delta$ Mass Loads for the Tributary at Low Flow.

Per Fig. 13, low-flow (0 to $25 \mathrm{cfs}$ ) results for the Tributary show periodic mass loadings of over 15,000 kg/day from the "Baseline +1 st Pond" (white) and, more sporadically, from the " 4 th Pond" (red). More consistently, a mass loading near 10,000 kg/day was added to the Tributary from the " 3 rd Pond" (yellow). 


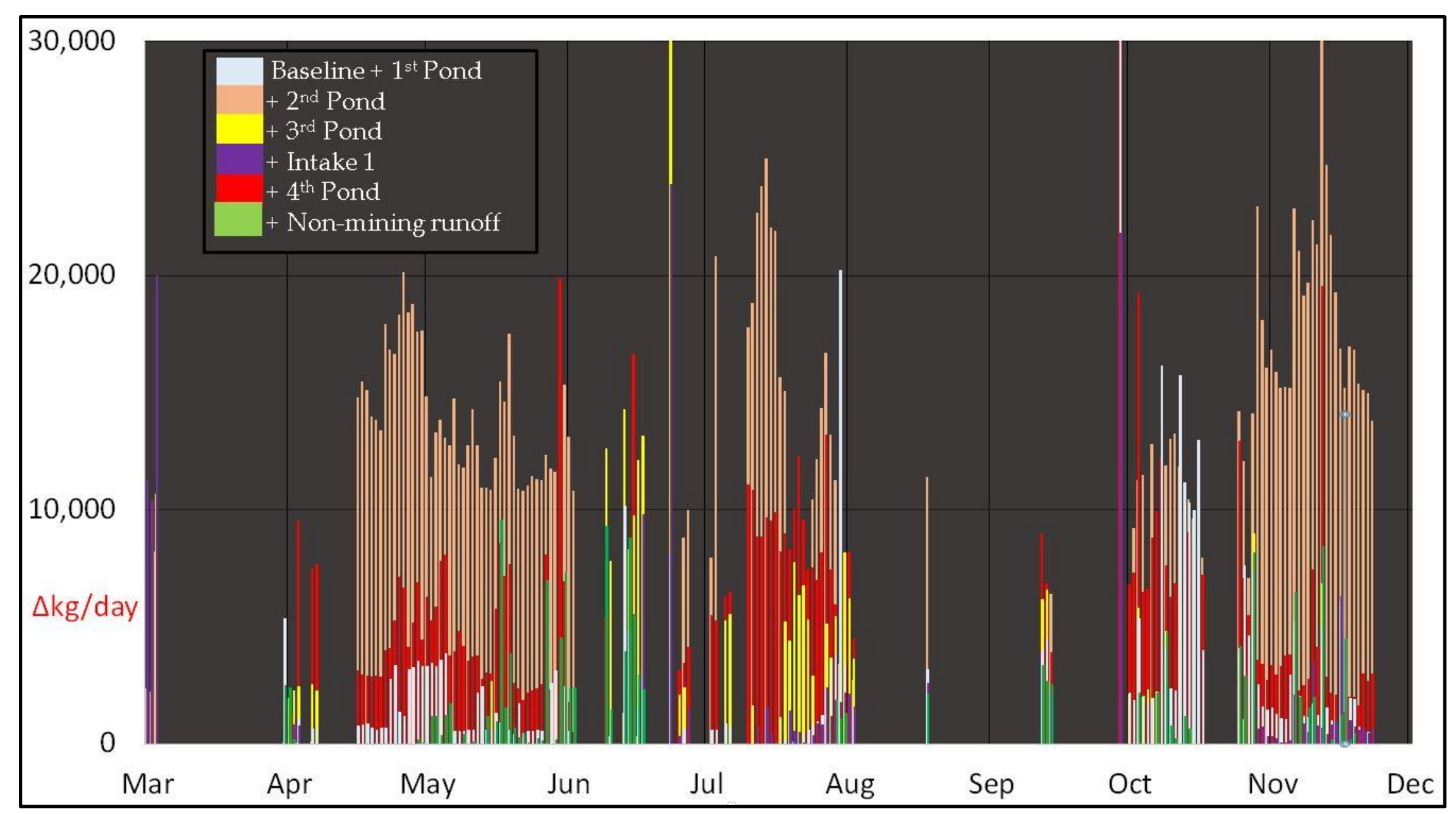

Figure 14. $\Delta$ Mass Loads for the Tributary at Moderate Flow.

Per Fig. 14, when the USGS Gage was between 25 to $200 \mathrm{cfs}$, the " ${ }^{\text {nd }}$ Pond" (tan or pink) most-consistently discharged the largest mass load to the Tributary at over $10,000 \mathrm{~kg} /$ day. The " $4{ }^{\text {th }}$ Pond" (red) was the second most 
significant source of mass loading to the Tributary at 5,000 kg/day. The discharge of the " 3 rd Pond" (yellow) sometimes added $5,000 \mathrm{~kg} / \mathrm{day}$.

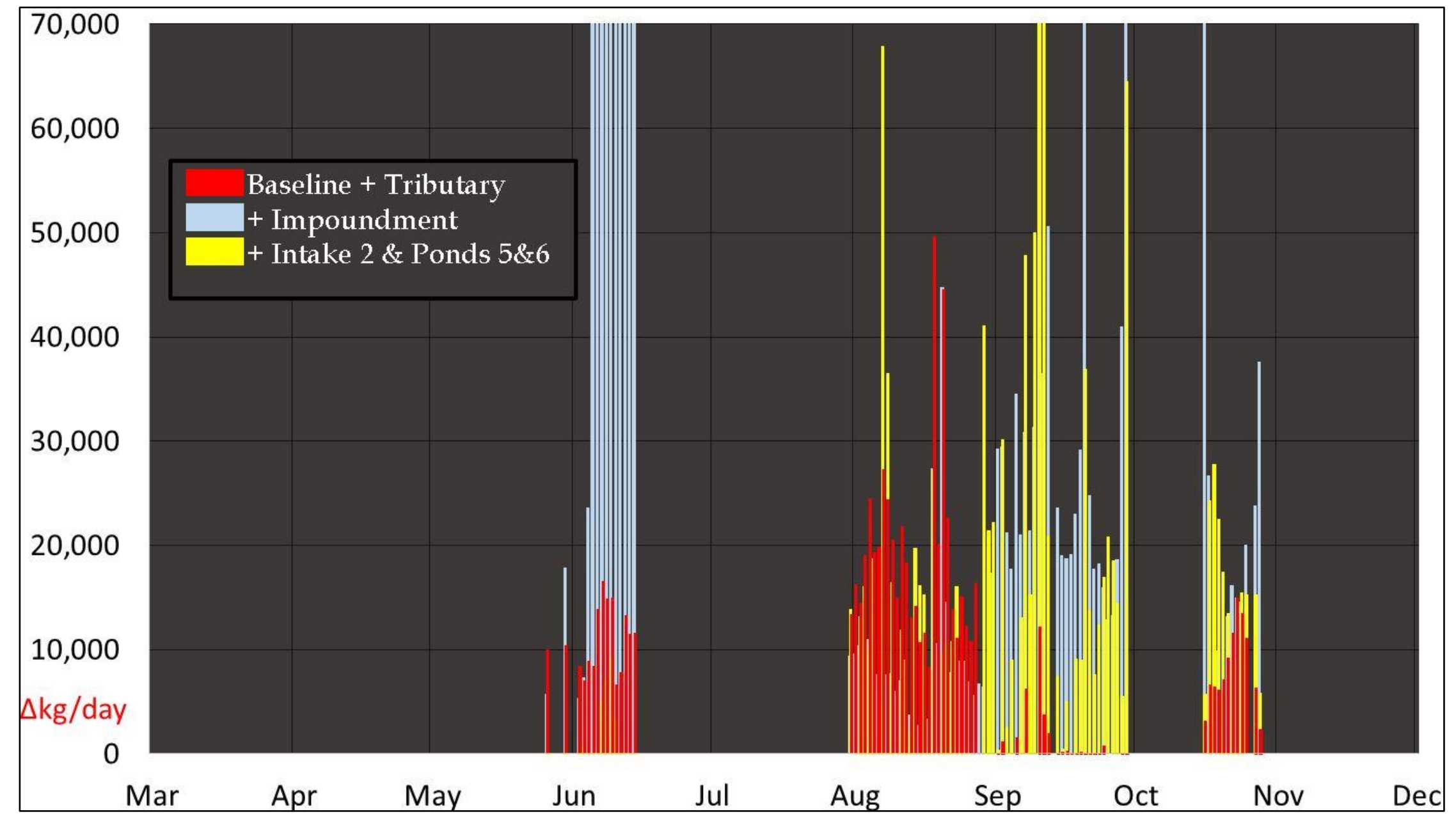

Figure 15. $\Delta$ Mass Loads for the Creek at Low Flow. 
Per Fig. 15, during low-flow conditions (0 to $25 \mathrm{cfs}$ ) the mass loading in the Creek periodically increased by over 70,000 kg/day from "+ Impoundment” (light blue). Discharges from the "Baseline + Tributary" (red) and from "+ Intake 2 and Ponds 5 and 6" (yellow) sometimes increased the mass loading in the Creek by over $10,000 \mathrm{~kg} /$ day. 


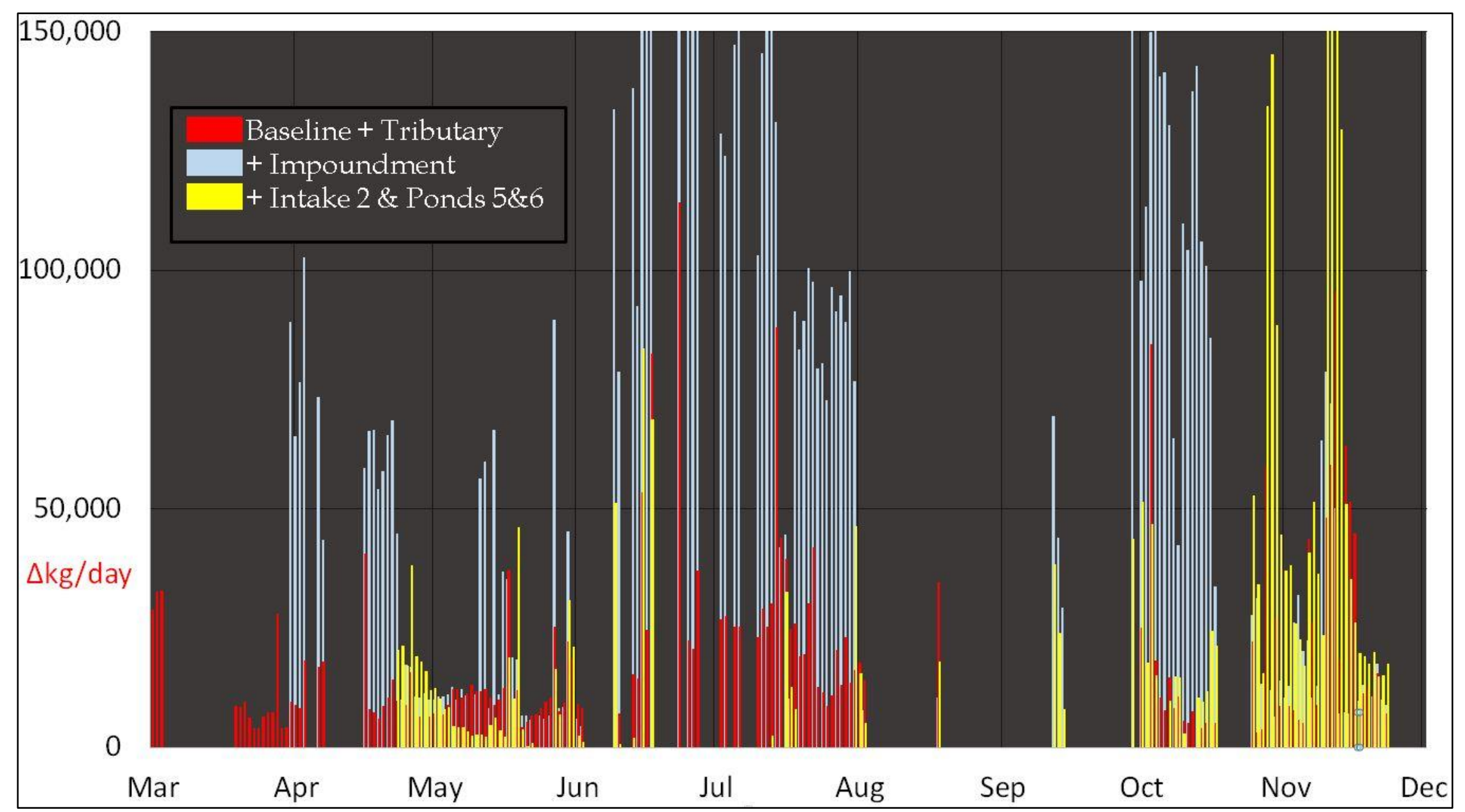

Figure 16. $\Delta$ Mass Loads for the Creek at Moderate Flow. 
Per Fig. 16, results for the Creek at 25 to 200 cfs indicate that the discharge from "+ Impoundment" (light blue) caused the largest change in mass load, sometimes exceeding 100,000 kg/day. Loading from "+ Intake 2 and Ponds 5and 6" (yellow) was comparatively high during October and November (although, as explained for Fig.12, some anomalous data resulted from the Creek going dry).

\section{Flow and Exceedance}

The results represented by Figs. 11 and 12 were used in conjunction with those for Fig. 13 through 16 to determine a corresponding flow for each event during which the $1,500 \mathrm{mg} / \mathrm{L}$ regulatory limit for TDS was exceeded. The same combined results were used to calculate the total amount of mass loading (for TDS) that the Creek and Tributary accepted while remaining in compliance. Details follow:

- Low-flow (0 to $25 \mathrm{cfs}$ ) exceedances for the Tributary occurred from mid-July through midSeptember and in early October. For the Creek they occurred sporadically in late August, and throughout September.

- The limit of TDS loading during low flow was at most about $10,000 \mathrm{~kg} /$ day into the Tributary and about 50,000 kg/day into the Creek.

- Moderate-flow (25 to $200 \mathrm{cfs}$ ) exceedances occurred for the Tributary in June, late September, and early November. For the Creek they occurred sporadically in mid-June, late July, and mid-August, and more continuously during mid-October.

- The compliance-related limit of TDS loading during moderate flow was at most 20,000 $\mathrm{kg} /$ day into the Tributary and 100,000 kg/day into the Creek.

- TDS loading during high flow was not well represented in the logged data, but the loading limit was estimated at 30,000 kg/day for the Tributary and 800,000 kg/day for the Creek.

In summary, the exceedances that occurred in both the Creek and the Tributary took place during moderate and low flows, and were not predictable based on either the flow regime or the season. The possible combinations of outfalls that could be operated while maintaining compliance can be predicted using the TDS loading limits for the Creek and Tributary (above) in conjunction with the yearly TDS totals (below). 


\section{$\underline{\text { TDS Yearly Totals }}$}

Investigation totals for TDS (Table 1) are the summed daily average mass loads calculated for each logging station, and the order of downstream succession is top to bottom. Data are missing for half of January, mid-February to mid-March, and all of December. The totals include results during high flow as well as those for moderate and low flows. Some dilution is implied where successive totals decrease in the downstream direction. The largest increases between successive stations were delivered by Ponds 2 and 4, and from the Impoundment.

Table 1. TDS totals by weight for 2015. Approximately two months of data are missing.

\begin{tabular}{|c|c|c|}
\hline Tributary Stations (Outfall/Intake) & Kilograms of TDS conveyed in 2015 & Tons of TDS conveyed in 2015 \\
\hline A (Baseline) & 297,143 & 328 \\
\hline B (Past Pond 1) & 857,383 & 945 \\
\hline C (Past Pond 2) & $\mathbf{2 , 6 5 1 , 6 0 3}$ & $\mathbf{2 , 9 2 3}$ \\
\hline D (Past Pond 3) & $2,046,591$ & 2,256 \\
\hline E (Past Intake 1) & $2,087,834$ & 2,301 \\
\hline F (Past Pond 4) & $\mathbf{2 , 8 7 4 , 6 0 3}$ & $\mathbf{3 , 1 6 9}$ \\
\hline G (End of Tributary) & $2,390,427$ & 2,635 \\
\hline Creek Stations (Outfall/Intake) & Kilograms of TDS conveyed in 2015 & Tons of TDS conveyed in 2015 \\
\hline \multirow{2}{*}{ H (Baseline) } & $10,182,094$ & 11,224 \\
\hline I (Past Tributary) & $14,938,841$ & 16,467 \\
\hline J (Past Impoundment) & $\mathbf{2 1 , 6 8 3 , 5 8 0}$ & $\mathbf{2 3 , 9 0 2}$ \\
\hline K (Past Intake 2 \& Ponds 5\&6) & $18,903,538$ & 20,838 \\
\hline
\end{tabular}

$\underline{\text { Offsite and Other Influences }}$

For the Tributary, there were no elevated TDS readings at the baseline station A (Fig. 11). However, offsite-derived TDS was detected on two occasions at baseline station $\mathrm{H}$ on the Creek. Offsite incursions occurred when flows were low; they caused TDS concentrations to double within the Creek, contributing to regulatory exceedances downstream (Fig. 12).

The role of evaporation in further concentrating TDS, especially in the larger ponds, has not yet been evaluated.

\section{$\underline{\text { Discussion }}$}

\section{Problematic Discharges Determined}

From analysis of the 2015 data, the influence of each outfall on Site-proximal waterways can be prioritized. Quantitatively and qualitatively, the problematic outfalls are as follows: 
- In low- and moderate-flow conditions, the Impoundment had the greatest influence on the Creek; it sporadically caused high concentrations of TDS in the Creek.

- In low-flow conditions, Pond 1 and then Pond 4 had the greatest influences on the Tributary. Their discharges frequently had a moderate influence on the TDS concentration in the Tributary.

- In moderate-flow conditions, Pond 2 and then Pond 4 had the greatest influences on the Tributary. Pond 2 frequently caused high concentrations of TDS while Pond 4 caused comparatively continuous and more moderate increases in TDS concentrations.

$\underline{\text { Remediation Strategies Outlined }}$

The occasional nature of the compliance problem sustained the hope that better management of the Site could achieve compliance without expensive measures. Options are discussed:

- Limiting problematic discharges during predetermined conditions would rely on surface water monitoring, adjustable pond flows, adequate storage capacity behind flow-restricted outfalls, and timely communications with site operators.

- Water treatment at problematic outfalls could employ a number of different methods to mitigate the sulfate portion of the TDS, but mitigating the chloride and sodium would require an expensive treatment such as reverse osmosis (Ericsson et al., 1994). In terms of energy consumption and brine disposal, the cost of reverse osmosis is considered to be disproportionate to the severity of the problem for the Site.

- Underground injection of wastewater to a deep mine depends on site-suitability and acquiring regulatory approval, but this avenue might be worth investigating.

- Modifying site operations and/or discharge locations would likely interfere with company goals, and would transfer problems from one location to another.

- The cost of source control is currently considered to be disproportionate to the severity of the problem for the Site.

\section{$\underline{\text { Site Management Recommendations }}$}

Recommendations are based on several observations and concepts. Firstly, each of the outlined remediation strategies requires continued water monitoring to verify progress. Of the monitoring methods available, automated (telemetry) systems provide the benefit of timely warnings prior to a noncompliant situation, and the current warning system does not include the Tributary. In 
addition, the most-problematic outfalls are identified, the project is not urgent, and there are significant aspects of the compliance situation that are beyond control. These factors suggest a continued iterative approach, beginning with the following:

- Determine how the flows of problematic outfalls on the Creek might be restricted in the event of increasing TDS, starting by calculating the storage capacities for existing ponds.

- Install a telemetry station to monitor the Tributary, and determine how the flows of outfalls that are problematic to the Tributary might be restricted.

\section{Design Recommendations}

To assist in planning future data logging or telemetry systems, design recommendations are included pertaining to experiences on this project and in-keeping with Miles (2009). These are geared toward professionalism and efficiency.

For telemetry work:

- Test the intended wireless service onsite prior to buying a modem;

- Design telemetry components to be removable and include a mount for a laptop or tablet;

- Use installers who are knowledgeable in computers, construction, and water monitoring;

- Find an installation location that is both secure and wireless-friendly; and

- Avoid complicated alerts to the client.

For data logging work:

- Know the site and how often it floods, any reported "maximum" flows probably pertain to the bankfull level;

- Plan a routine to access the stations, perhaps the technician has to reach underwater; etc.;

- Place monuments behind obstacles (large trees, bedrock ledge) to protect against collisions;

- Beware of locations where deep water is close to the shore as this can indicate instability;

- For TDS-related projects, consider using saltwater-capable loggers (even in freshwater);

- Plan for monthly removal of silt, perhaps along with the optical uploading of data; and

- Budget for data compilation and spare data loggers. In this investigation it happened that the differences between the flows of many stations were often less than the inherent methodological error; this redundancy turned out to be helpful (see the discussion of substituted data for Fig. 11). 


\section{Acknowledgements}

- Bill Walker and Tyler Chatriand, who began and helped develop the project. Lindsay Wolfendale, Brian Becker, and John McCollums for assisting in fieldwork. Lindsey Peterson, for editing and support.

\section{Literature Cited}

Ericsson, B. and B. Hallmans, 1994. Treatment and disposal of saline wastewater from coal mines in Poland. Desalination, 98(1-3): pp. 239-248. http://dx.doi.org/10.1016/0011-9164(94)00148$\underline{0}$.

Hem, J.D., 1970. Study and interpretation of the chemical characteristics of natural water, (2 ${ }^{\text {nd }}$ ed.). U.S. Geological Survey Water-Supply Paper, 1473, p. 363.

Lefebvre, R., D. Hockley, J. Smolensky, and P. Gélinas, 2001. Multiphase transfer processes in waste rock piles producing acid mine drainage, 1: Conceptual model and system characterization. Journal of Contaminant Hydrology, 52(1-4): pp. 137-164. http://dx.doi.org/10.1016/S0169-7722(01)00156-5.

Lieberman, T.D., R.F. Middelburg, and S.A. Irvine, 1987. User's manual for estimation of dissolved-solids concentrations and loads in surface water. U.S. Geological Survey WaterResources Investigations Report 86-4124: p. 4.

Miles, E.J. 2009. Guidelines for shallow water quality monitoring, continuous monitoring station: selection, assembly and construction. Special report No. 412 in Applied Marine Science and Ocean Engineering. Virginia Institute of Marine Science, College of William and Mary, Gloucester Point, VA.

Radtke, D.B., J.V. Davis, and F.D. Wilde, 2005. Specific electrical conductance (ver.1.2): U.S. Geological Survey Techniques of Water-Resources Investigations, Book 9, chapter A6, section 6.3: p. 22.

Ritchie, A.I.M., 1994. The waste rock environment, In: Environmental Geochemistry of Sulfide Mine-wastes, Mineralogical Association of Canada Shortcourse Handbook (J.L. Jambor and D.W. Blowes, eds.), vol. 22: pp. 133-161. 
Rupert, L.F., S.J. Tewalt, L.J. Bragg, and R.N. Wallack, 1999. A digital resource model of the Upper Pennsylvania Pittsburgh coal bed, Monongahela Group, Northern Appalachian Basin Coal Region, USA. International Journal of Coal Geology, 41: pp. 3-24. http://dx.doi.org/10.1016/S0166-5162(99)00009-924.

Smith, L., D.L. López, R. Beckie, K.A. Morin, R. Dawson, and W. Price, 1995. Hydrogeology of waste rock dumps: Ottawa, Canada. Department of Natural Resources, Canada Center for Mineral and Energy Technology: p. 156.

Thirumalini, S. and K. Joseph, 2009. Correlation between electrical conductivity and total dissolved solids in natural waters. Malaysian Journal of Science, 28(1): pp. 55-61.

Turnipseed, D.P. and V.B. Sauer. 2010. Discharge Measurements at Gaging Stations. U.S. Geological Survey Techniques and Methods, Book 3, Chapter A8: p. 87.

Walton, N.R.G. 1989. Electrical conductivity and total dissolved solids. What is their precise relationship? Desalination, 72(3): pp. 275-292. http://dx.doi.org/10.1016/00119164(89)80012-8. 